\title{
One-year eye-to-eye comparison of wavefront-guided versus wavefront-optimized laser in situ keratomileusis in hyperopes
}

This article was published in the following Dove Press journal:

Clinical Ophthalmology

12 November 2014

Number of times this article has been viewed

\author{
Christopher S Sáles \\ Edward E Manche \\ Byers Eye Institute, Stanford \\ University School of Medicine, \\ Palo Alto, CA, USA
}

Correspondence: Edward E Manche Byers Eye Institute, Stanford University School of Medicine, 2452 Watson Court; Palo Alto, CA 94303, USA

Tel +l 6507236995

Fax + I 6505658297

Email edward.manche@stanford.edu
Background: To compare wavefront (WF)-guided and WF-optimized laser in situ keratomileusis (LASIK) in hyperopes with respect to the parameters of safety, efficacy, predictability, refractive error, uncorrected distance visual acuity, corrected distance visual acuity, contrast sensitivity, and higher order aberrations.

Methods: Twenty-two eyes of eleven participants with hyperopia with or without astigmatism were prospectively randomized to receive WF-guided LASIK with the VISX CustomVue S4 IR or WF-optimized LASIK with the WaveLight Allegretto Eye-Q $400 \mathrm{~Hz}$. LASIK flaps were created using the $150-\mathrm{kHz}$ IntraLase iFS. Evaluations included measurement of uncorrected distance visual acuity, corrected distance visual acuity, $<5 \%$ and $<25 \%$ contrast sensitivity, and WF aberrometry. Patients also completed a questionnaire detailing symptoms on a quantitative grading scale.

Results: There were no statistically significant differences between the groups for any of the variables studied after 12 months of follow-up (all $P>0.05$ ).

Conclusion: This comparative case series of 11 subjects with hyperopia showed that WF-guided and WF-optimized LASIK had similar clinical outcomes at 12 months.

Keywords: wavefront, hyperopic, LASIK

\section{Introduction}

Hyperopic laser in situ keratomileusis (LASIK) technology has continued to evolve since its inception in the 1990s. Early, conventional approaches to treating hyperopia were effective at correcting simple spherocylinder refractive errors with good stability, but had the undesirable effect of inducing higher order aberrations ( $\mathrm{HOAs})^{1,2}$ by altering the cornea's natural asphericity. ${ }^{3-5}$ Ameliorating this phenomenon has been the focus of developing more sophisticated wavefront (WF)-based ablation algorithms.

WF-based treatments can be classified into two broad categories: WF-optimized and WF-guided algorithms. The WF-optimized approach considers an eye's refractive error and preoperative keratometry, in conjunction with the variable ablation depths of peripherally delivered laser pulses, to apply a precalculated aspheric ablation that aims to limit induced spherical aberrations. The WF-guided approach renders a customized treatment plan based on an eye's unique preoperative aberrometry with the intent of not only minimizing induced postoperative aberrations but also reducing or eliminating preoperative HOAs.

In this pilot, prospective, randomized, eye-to-eye comparison of hyperopes, we compared WF-guided to WF-optimized treatments. The primary outcome measures included uncorrected distance visual acuity (UDVA), refractive stability, refractive 
predictability, contrast sensitivity, HOAs, loss of corrected distance visual acuity (CDVA), and a validated quantitative questionnaire.

\section{Methods}

Twenty-two eyes of eleven participants with hyperopia with or without astigmatism were randomized to receive either WF-guided LASIK with the VISX Star CustomVue S4 IR (Abbott Medical Optics Inc., Santa Ana, CA, USA) or WF-optimized LASIK with the WaveLight Allegretto Eye-Q $400 \mathrm{~Hz}$ (Alcon, Inc., Hüenberg, Switzerland) in their dominant eye and the alternative in their other eye. All participants provided their written informed consent after full disclosure of the nature of the research. The study was conducted at the Stanford University Eye Laser Center and adhered to the tenets of the Declaration of Helsinki as well as the Health Insurance Portability and Accountability Act. The authors (CSS and EEM) had no financial disclosures that might preclude objective conduct of the study.

Inclusion criteria included a stable refraction with a change of less than 0.50 diopters (D) of sphere or cylinder in the last year, best corrected visual acuity of 20/20 or better, age older than 21 years, and ability to participate in postoperative examinations for at least 12 months. Patients were excluded for use of rigid gas-permeable contact lenses; severe dry eye or blepharitis; corneal pathology (ie, recurrent erosion syndrome, basement membrane disease, keratoconus, and irregular corneal mires on central keratometry); pachymetry whereby the postoperative thickness would be less than $250 \mu \mathrm{m}$ below the flap; baseline standard manifest refraction with a difference of $0.75 \mathrm{D}$ or more in sphere power or $0.50 \mathrm{D}$ in cylinder power as compared to the baseline standard cycloplegic refraction; history of herpes zoster or herpes simplex; corneal warpage (ie, contact-lens induced topographical abnormalities); and certain systemic diseases or conditions (ie, connective tissue disease, diabetes, pregnancy, lactation, immunocompromised state, and severe atopy). Also excluded were patients with sensitivity to the study's concomitant medications and patients participating in a clinical trial for another ophthalmic drug or device.

Patients who met the preceding criteria underwent a comprehensive preoperative evaluation, including a history, $<5 \%$ and $<25 \%$ contrast sensitivity (Precision Vision, La Salle, Illinois, USA), slit-lamp biomicroscopy, Goldmann applanation tonometry, infrared pupillometry (Neuroptics, Irvine, CA, USA), dilated fundus examination, manifest and cycloplegic refraction using Early Treatment Diabetic Retinopathy Study charts, computerized corneal topography, and WF aberrometry using the VISX WaveScan aberrometer. Patients completed a questionnaire that has been employed and validated in previous contralateral eye studies. ${ }^{6-8}$ The questionnaire details symptoms quantified on a grading scale of 0 (no symptoms) to 10 (severe symptoms) for each of the following parameters: glare under night and day conditions, haze, halos, clarity under night and day conditions, dry eye symptom frequency and severity, foreign body sensation, vision fluctuation, and ghosting. Patients were also asked to grade their overall vision on a scale of 0 (excellent vision) to 10 (poor vision) as well as whether they preferred one eye to the other eye (Table 1). The LASIK surgeries were performed in a bilateral simultaneous fashion to negate any learning curve, and the questionnaire was administered preoperatively and postoperatively at months 1 , 3,6 , and 12 .

WF aberrations were measured preoperatively and postoperatively with a physiologic pupil under controlled scotopic conditions with the WaveScan aberrometer, which was also used to plan WF-guided treatments. All eyes had pupil sizes that measured $\geq 6 \mathrm{~mm}$ preoperatively and postoperatively. Although luminance was not measured, all aberrometry was performed in the same room. To account for the potential variability caused by measuring HOAs at different pupil diameters, aberrometry measurements that were taken when the pupil was within $0.25 \mathrm{~mm}$ of the preoperative diameter were used for data analysis. Six readings from each eye were taken at each visit before and after surgery when possible, and the best acquisition was used for analysis as determined by the clearest centroid image.

All surgeries were performed at Stanford University Eye Laser Center by a single surgeon (EEM). LASIK flaps were

Table I Patient questionnaire

\begin{tabular}{|c|c|}
\hline Parameter & Scale $^{a}$ \\
\hline Glare, night & None: 0 - Disabling: 10 \\
\hline Glare, day & None: 0 - Disabling: 10 \\
\hline Haze & None: 0 - Disabling: 10 \\
\hline Halos & None: 0 - Disabling: 10 \\
\hline Clarity, night & No problem: 0 - Disabling: 10 \\
\hline Clarity, day & No problem: 0 - Disabling: 10 \\
\hline Vision is excellent & Agree: 0 - Disagree: 10 \\
\hline Dry eye & No problem: 0 - Disabling: 10 \\
\hline Dry eye severity & No problem: 0 - Disabling: 10 \\
\hline Foreign body sensation & Never: 0 - Always: 10 \\
\hline Vision fluctuates diurnally & Never: 0 - Always: 10 \\
\hline Difficulty due to ghosting & None: 0 - Extreme Difficulty: 10 \\
\hline Preferred eye & Same vs Right vs Left ${ }^{\mathrm{b}}$ \\
\hline
\end{tabular}

Notes: The validated questionnaire was completed preoperatively and postoperatively at months I, 6, and I2. Participants completed the questionnaire for each eye. a Scale was presented as discrete, whole numbers: $0,1,2$ etc. 'Subjects' preferred eye was recoded into wavefront guided vs wavefront optimized for analysis. 
created using the $150-\mathrm{kHz}$ IntraLase iFS (Abbott Medical Optics Inc.). A $9.2 \mathrm{~mm}$ diameter, superior hinge with a $105 \mu \mathrm{m}$ programmed flap depth setting was used, and intraoperative ultrasonic pachymetry (Sonogage, Cleveland, $\mathrm{OH}$, USA) was performed in all cases. Patients were prospectively evaluated at 1 day, 1 week, 1 month, 3 months, 6 months, and 12 months; the data from evaluations performed at 1 day and 1 week are not presented.

Statistical analyses were performed with a commercially available software package (SPSS for Mac, Version 20.0; IBM Corporation, Armonk, NY, USA). Normal distribution of the preoperative and postoperative data was assessed by the Shapiro-Wilk test. All comparisons of means were performed using a Wilcoxon signed-rank test, which is the nonparametric analog of the paired $t$-test and is more accurate for a small sample size. Correlations between binary variables were calculated using McNemar's exact test, which is an ana$\log$ of the chi-squared test and also considered more accurate for a small sample size. Correlations between multinomial categorical variables were calculated using the Monte Carlo test. All $P$-values were two sided and considered statistically significant when $<0.05$.

\section{Results}

Seven participants comprising 14 of the 22 eyes enrolled were female $(63.6 \%)$. The mean age of the cohort was $52.6 \pm 6.5$ years (range, 40-60 years). The computergenerated schedule resulted in eight distance-dominant eyes randomized to the WF-guided group compared to three randomized to the WF-optimized group (72.7\% [41.8-103.6] vs $27.3 \%$ [-3.6-58.2], $P=0.03)$. Preoperative astigmatism ranged from $0.00 \mathrm{D}$ to $2.50 \mathrm{D}$ and sphere ranged from $0.00 \mathrm{D}$ to $3.00 \mathrm{D}$. At baseline, there were no statistically significant differences between the WF-guided and WF-optimized groups for all studied parameters, including UDVA, contrast sensitivity, refractive error, and HOAs (all $P>0.05$ ) (Table 2).

\section{Efficacy and safety}

There were no statistically significant differences between the WF-guided and WF-optimized groups at all postoperative months in mean UDVA and CDVA (all $P>0.05$ ) (Table 2). The frequencies of achieving postoperative UDVA of 20/16 or better, $20 / 20$ or better, $20 / 30$ or better, $20 / 40$ or better, or $20 / 50$ or better were not statistically different between the groups (all $P>0.05$ ) (Table 3, Figure 1A and B). Moreover, the frequencies with which the groups maintained their preoperative CDVA, lost one or two or more lines, or gained one or two or more lines after undergoing LASIK were not statistically different from each other either (all $P>0.05$ ) (Table 3, Figure 1C and D).

\section{Contrast sensitivity}

There were no statistically significant differences in mean CDVA between the groups under $<5 \%$ and $<25 \%$ contrast sensitivity conditions at all postoperative time intervals studied (all $P>0.05$ ) (Table 2). Five and twenty-five percent contrast sensitivity decreased less than one Early Treatment Diabetic Retinopathy Study line in the WF-guided group at 12 months compared to preoperative measurements, but these losses were not statistically significant (preoperative vs 12 months: $<5 \%$ contrast sensitivity, $0.19 \pm 0.09$ vs $0.24 \pm 0.08$ logarithm of the minimal angle of resolution [logMAR] [Snellen equivalent of slightly worse than 20/30 vs slightly better than 20/35]; $<25 \%$ contrast sensitivity, $0.17 \pm 0.06$ vs $0.24 \pm 0.08 \log$ MAR [slightly better than $20 / 30$ vs slightly better than 20/35]; $P=0.30, P=0.09$, respectively). In the WF-optimized group, $5 \%$ contrast sensitivity showed a statistically significant decrease of almost one Early Treatment Diabetic Retinopathy Study line at 12 months compared to preoperative measurements; $25 \%$ contrast sensitivity also decreased by less than one line, but did not reach statistical significance (preoperative vs 12 months: $<5 \%$ contrast sensitivity, $0.18 \pm 0.10$ vs $0.26 \pm 0.10 \log$ MAR [slightly worse than $20 / 30$ vs slightly worse than $20 / 35$ ]; $<25 \%$ contrast sensitivity, $0.19 \pm 0.07$ vs $0.25 \pm 0.14 \log$ MAR [slightly worse than $20 / 30$ vs slightly better than $20 / 35$ ]; $P=0.04, P=0.14$, respectively).

\section{Refractive error, predictability, and stability}

There were no statistically significant differences in mean sphere or spherical equivalent (SE) at all postoperative months (all $P>0.05$ ) (Table 2, Figure 1E and F). At all intervals studied, there were also no statistically significant differences between the groups with regard to the frequency that each achieved an SE within $\pm 0.25 \mathrm{D}, \pm 0.50 \mathrm{D}$, and $\pm 1.00 \mathrm{D}$ of emmetropia (all $P>0.05$ ); there was, however, a trend that failed to reach statistical significance favoring approximately a $40 \%$ higher frequency of attaining a refraction within $\pm 0.25 \mathrm{D}$ of emmetropia in the WF-guided group at postoperative month 12 (81.8\% [48.2-97.7] vs 36.4\% [10.9-69.2]; $P=0.13$ ) (Table 3, Figure 2A and B). There was no statistically significant difference in the proportion of each group to have an SE change of more than $0.50 \mathrm{D}$ between months 3 and 12 (Figure 2E and F). 
Table 2 Preoperative and postoperative parameters comparing WF-optimized to WF-guided hyperopic LASIK

\begin{tabular}{|c|c|c|c|}
\hline \multirow[t]{2}{*}{ Parameter } & \multicolumn{2}{|c|}{ Mean \pm standard deviation, range } & \multirow[t]{2}{*}{$P^{a}$} \\
\hline & WF-guided $(n=I I)$ & WF-optimized $(n=I I)$ & \\
\hline \multicolumn{4}{|l|}{ Preoperative } \\
\hline UDVA $^{\mathrm{b}}$ & $0.36 \pm 0.25,-0.10$ to 0.80 & $0.40 \pm 0.20,0.10$ to 0.80 & 0.56 \\
\hline $\mathrm{CDVA}^{\mathrm{b}}$ & $-0.15 \pm 0.05,-0.20$ to -0.10 & $-0.15 \pm 0.07,-0.20$ to 0.00 & 1.00 \\
\hline CDVA $^{b}<5 \%$ contrast & $0.19 \pm 0.09,0.10$ to 0.40 & $0.18 \pm 0.10,0.00$ to 0.30 & 0.43 \\
\hline CDVA $^{\mathrm{b}}<25 \%$ contrast & $0.17 \pm 0.06,0.10$ to 0.30 & $0.19 \pm 0.07,0.10$ to 0.30 & 0.60 \\
\hline Sphere (D) & $\mathrm{I} .30 \pm 0.8 \mathrm{I}, 0.00$ to 3.00 & $1.61 \pm 0.66,0.25$ to 2.75 & 0.23 \\
\hline Astigmatism (D) & $0.86 \pm 0.63,0.00$ to 2.50 & $0.64 \pm 0.57,0.00$ to 2.00 & 0.12 \\
\hline Spherical equivalent (D) & $1.73 \pm 0.66,0.88$ to 3.38 & $1.93 \pm 0.64,1.25$ to 3.25 & 0.68 \\
\hline Coma & $0.21 \pm 0.15,0.06$ to 0.60 & $0.18 \pm 0.13,0.05$ to 0.47 & 0.48 \\
\hline Trefoil & $0.13 \pm 0.09,0.04$ to 0.31 & $0.14 \pm 0.10,0.04$ to 0.38 & 0.61 \\
\hline RMS error $(\mu \mathrm{m})$ & $0.35 \pm 0.15,0.17$ to 0.72 & $0.36 \pm 0.17,0.09$ to 0.59 & 0.93 \\
\hline \multicolumn{4}{|l|}{ Postoperative month I } \\
\hline UDVA $^{\mathrm{b}}$ & $-0.06 \pm 0.15,-0.20$ to 0.20 & $-0.05 \pm 0.17,-0.20$ to 0.40 & 1.00 \\
\hline $\mathrm{CDVA}^{\mathrm{b}}$ & $-0.16 \pm 0.09,-0.30$ to 0.00 & $-0.14 \pm 0.09,-0.20$ to 0.00 & 0.46 \\
\hline $\mathrm{CDVA}^{\mathrm{b}}<5 \%$ contrast & $0.23 \pm 0.09,0.10$ to 0.40 & $0.25 \pm 0.08,0.10$ to 0.40 & 0.83 \\
\hline CDVA $^{b}<25 \%$ contrast & $0.19 \pm 0.08,0.10$ to 0.40 & $0.22 \pm 0.10,0.10$ to 0.40 & 0.75 \\
\hline Sphere (D) & $-0.4 I \pm 0.36,-1.00$ to 0.00 & $-0.4 I \pm 0.32,-1.25$ to 0.00 & 1.00 \\
\hline Astigmatism (D) & $0.25 \pm 0.39,0.00$ to 1.25 & $0.45 \pm 0.38,0.00$ to 1.00 & 0.32 \\
\hline Spherical equivalent (D) & $-0.30 \pm 0.26,-0.75$ to 0.12 & $-0.18 \pm 0.29,-0.75$ to 0.25 & 0.23 \\
\hline Coma & $0.13 \pm 0.08,0.00$ to 0.26 & $0.16 \pm 0.09,0.04$ to 0.29 & 0.37 \\
\hline Trefoil & $0.10 \pm 0.05,0.04$ to 0.17 & $0.14 \pm 0.12,0.01$ to $0.4 \mathrm{I}$ & 0.28 \\
\hline RMS error $(\mu \mathrm{m})$ & $0.23 \pm 0.06,0.12$ to 0.32 & $0.28 \pm 0.11,0.15$ to 0.50 & 0.15 \\
\hline \multicolumn{4}{|l|}{ Postoperative month 3} \\
\hline UDVA $^{\mathrm{b}}$ & $-0.10 \pm 0.21,-0.30$ to 0.40 & $-0.11 \pm 0.13,-0.20$ to 0.20 & 1.00 \\
\hline $\mathrm{CDVA}^{\mathrm{b}}$ & $-0.19 \pm 0.10,-0.30$ to 0.00 & $-0.16 \pm 0.05,-0.20$ to -0.10 & 0.72 \\
\hline $\mathrm{CDVA}^{\mathrm{b}}<5 \%$ contrast & $0.22 \pm 0.09,0.10$ to 0.40 & $0.24 \pm 0.08,0.10$ to 0.40 & 0.86 \\
\hline CDVA $^{b}<25 \%$ contrast & $0.20 \pm 0.12,0.10$ to 0.50 & $0.20 \pm 0.07,0.10$ to 0.30 & 1.00 \\
\hline Sphere (D) & $-0.28 \pm 0.28,-0.75$ to 0.25 & $-0.45 \pm 0.35,-1.25$ to 0.00 & 0.30 \\
\hline Astigmatism (D) & $0.20 \pm 0.26,0.00$ to 0.75 & $0.30 \pm 0.33,0.00$ to 0.75 & 0.49 \\
\hline Spherical equivalent (D) & $-0.18 \pm 0.25,-0.62$ to 0.25 & $-0.30 \pm 0.29,-0.88$ to 0.12 & 0.40 \\
\hline Coma & $0.15 \pm 0.13,0.05$ to $0.5 \mathrm{I}$ & $0.16 \pm 0.11,0.03$ to 0.39 & 0.77 \\
\hline Trefoil & $0.09 \pm 0.04,0.03$ to 0.17 & $0.1 \mathrm{I} \pm 0.06,0.02$ to 0.22 & 0.23 \\
\hline RMS error $(\mu \mathrm{m})$ & $0.23 \pm 0.13,0.10$ to 0.55 & $0.28 \pm 0.13,0.10$ to 0.53 & 0.16 \\
\hline \multicolumn{4}{|l|}{ Postoperative month 6} \\
\hline UDVA $^{\mathrm{b}}$ & $-0.13 \pm 0.11,-0.30$ to 0.10 & $-0.08 \pm 0.13,-0.20$ to 0.20 & 0.52 \\
\hline $\mathrm{CDVA}^{\mathrm{b}}$ & $-0.17 \pm 0.10,-0.30$ to 0.00 & $-0.18 \pm 0.06,-0.30$ to -0.10 & 0.93 \\
\hline CDVA $^{b}<5 \%$ contrast & $0.19 \pm 0.07,0.10$ to 0.30 & $0.21 \pm 0.07,0.10$ to 0.30 & 0.67 \\
\hline CDVA $^{\mathrm{b}}<25 \%$ contrast & $0.19 \pm 0.10,0.10$ to 0.40 & $0.20 \pm 0.09,0.10$ to 0.30 & 0.95 \\
\hline Sphere (D) & $-0.25 \pm 0.33,-0.75$ to 0.50 & $-0.4 I \pm 0.23,-0.75$ to 0.00 & 0.20 \\
\hline Astigmatism (D) & $0.14 \pm 0.17,0.00$ to 0.50 & $0.34 \pm 0.26,0.00$ to 0.75 & 0.07 \\
\hline Spherical equivalent (D) & $-0.16 \pm 0.36,-0.62$ to 0.75 & $-0.24 \pm 0.26,-0.62$ to 0.25 & 0.34 \\
\hline Coma & $0.15 \pm 0.09,0.02$ to 0.33 & $0.15 \pm 0.15,0.02$ to 0.42 & 0.64 \\
\hline Trefoil & $0.1 \mathrm{I} \pm 0.06,0.03$ to $0.2 \mathrm{I}$ & $0.1 \mathrm{I} \pm 0.06,0.0 \mathrm{I}$ to 0.20 & 0.70 \\
\hline RMS error $(\mu \mathrm{m})$ & $0.25 \pm 0.08,0.09$ to 0.38 & $0.29 \pm 0.14,0.11$ to 0.52 & 0.33 \\
\hline \multicolumn{4}{|l|}{ Postoperative month 12} \\
\hline UDVA $^{b}$ & $-0.11 \pm 0.09,-0.30$ to 0.00 & $-0.08 \pm 0.12,-0.20$ to 0.20 & 1.00 \\
\hline $\mathrm{CDVA}^{\mathrm{b}}$ & $-0.18 \pm 0.08,-0.30$ to 0.10 & $-0.15 \pm 0.07,-0.20$ to 0.00 & 0.43 \\
\hline CDVA $^{b}<5 \%$ contrast & $0.24 \pm 0.08,0.10$ to 0.40 & $0.26 \pm 0.10,0.20$ to 0.50 & 0.60 \\
\hline CDVA $^{\mathrm{b}}<25 \%$ contrast & $0.24 \pm 0.08,0.10$ to 0.40 & $0.25 \pm 0.14,0.10$ to 0.50 & 1.00 \\
\hline Sphere (D) & $-0.23 \pm 0.3 \mathrm{I},-0.75$ to 0.50 & $-0.25 \pm 0.47,-0.75$ to 0.50 & 0.89 \\
\hline Astigmatism (D) & $0.20 \pm 0.27,0.00$ to 0.75 & $0.23 \pm 0.33,-0.25$ to 0.75 & 1.00 \\
\hline Spherical equivalent (D) & $-0.12 \pm 0.32,-0.75$ to 0.50 & $-0.1 I \pm 0.46,-0.75$ to 0.62 & 0.90 \\
\hline Coma & $0.18 \pm 0.12,0.02$ to 0.42 & $0.19 \pm 0.14,0.05$ to 0.47 & 0.64 \\
\hline Trefoil & $0.09 \pm 0.04,0.05$ to 0.19 & $0.1 I \pm 0.05,0.02$ to 0.18 & 0.28 \\
\hline RMS error $(\mu \mathrm{m})$ & $0.26 \pm 0.10,0.13$ to 0.45 & $0.29 \pm 0.13,0.13$ to 0.53 & 0.44 \\
\hline
\end{tabular}




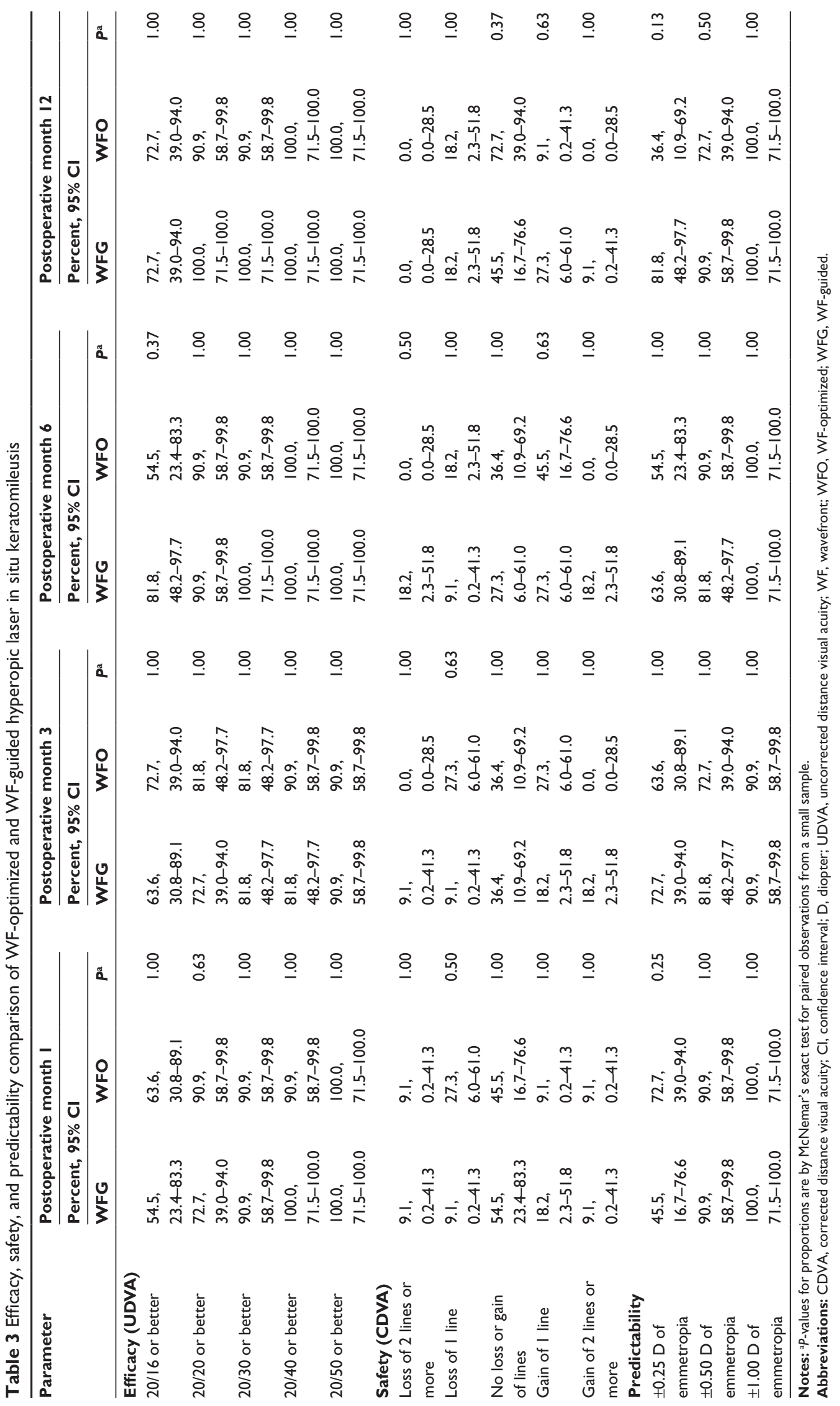


A

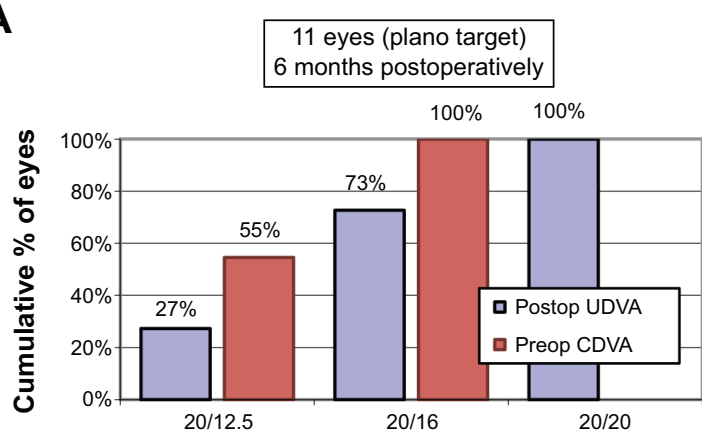

Cumulative Snellen visual acuity (20/x or better)

Wavefront-guided hyperopic LASIK uncorrected distance visual acuity

C

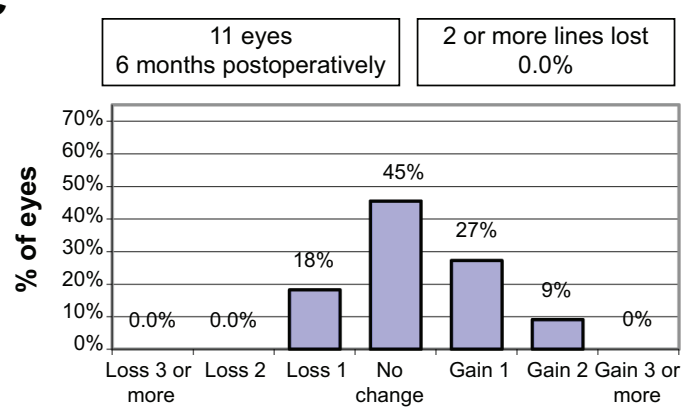

Change in Snellen lines of CDVA

Wavefront-guided hyperopic LASIK change in corrected distance visual acuity

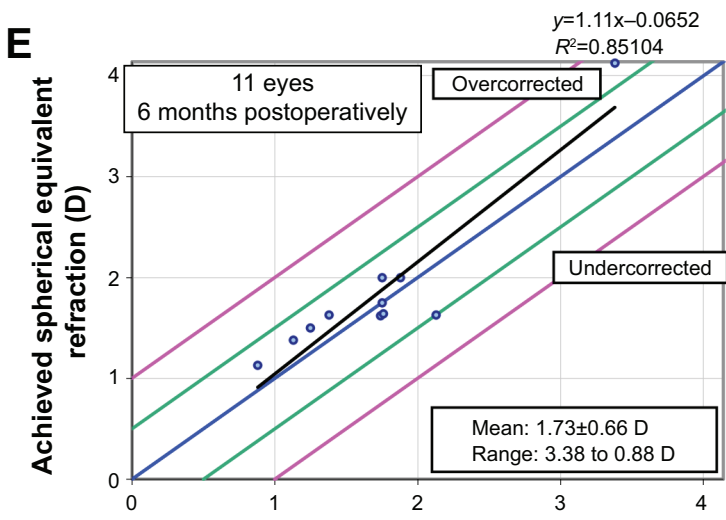

Attempted spherical equivalent refraction (D)

Wavefront-guided hyperopic LASIK spherical equivalent attempted vs achieved
B

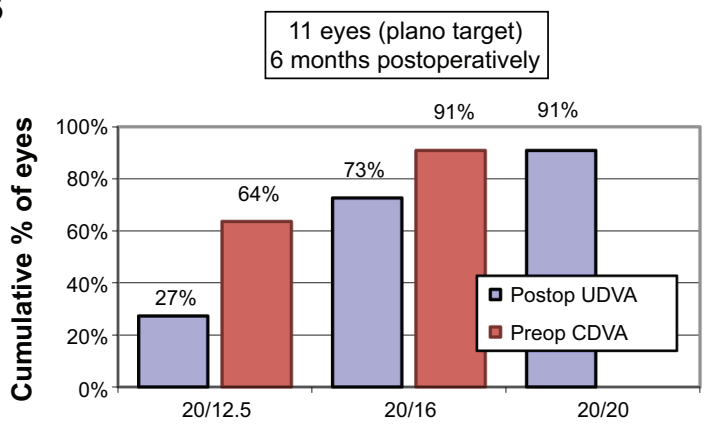

Cumulative Snellen visual acuity (20/x or better)

Wavefront-optimized hyperopic LASIK uncorrected distance visual acuity

D

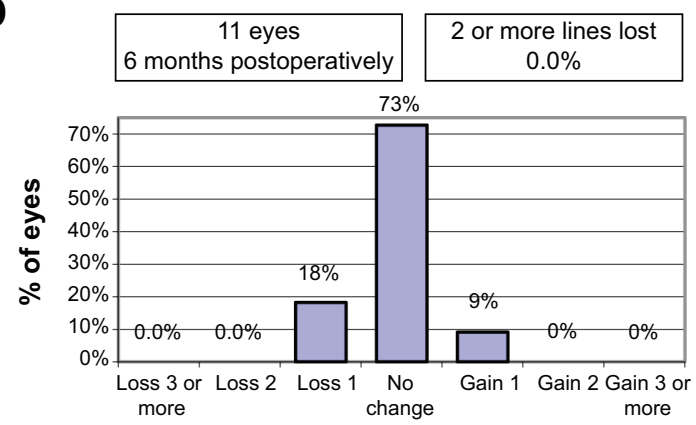

Change in Snellen lines of CDVA

Wavefront-optimized hyperopic LASIK change in corrected distance visual acuity

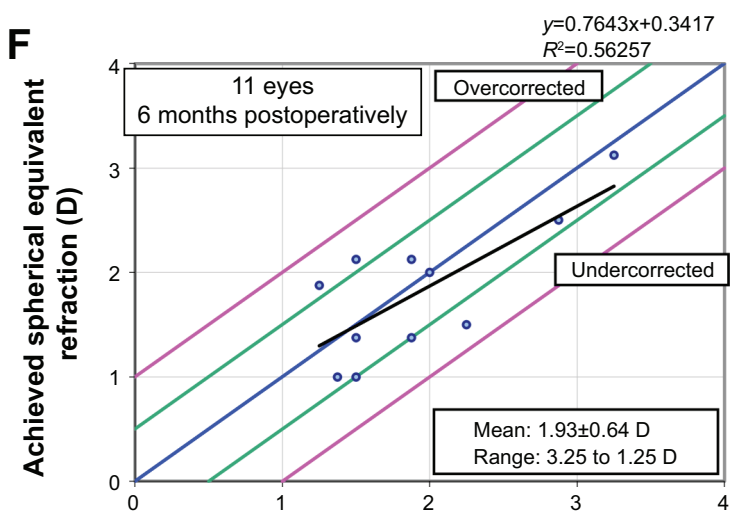

Attempted spherical equivalent refraction (D)

Wavefront-optimized hyperopic LASIK spherical equivalent attempted vs achieved

Figure I Comparison of WF-guided LASIK and WF-optimized LASIK standard graphs.

Notes: (A) Uncorrected visual acuity outcomes of WF-guided LASIK at 12 months. (B) Uncorrected visual acuity outcomes of WF-optimized LASIK at 12 months. (C) Change in corrected distance visual acuity after WF-guided LASIK at 12 months. (D) Change in corrected distance visual acuity after WF-optimized LASIK at 12 months. (E) Distribution of achieved spherical equivalent outcomes after WF-guided LASIK at 12 months. (F) Distribution of achieved spherical equivalent outcomes after WFoptimized LASIK at I2 months.

Abbreviations: CDVA, corrected distance visual acuity; D, diopter; LASIK, laser in situ keratomileusis; Preop, preoperative; Postop, postoperative; UDVA, uncorrected distance visual acuity; WF, wavefront.

There was a trend favoring almost one quarter $\mathrm{D}$ less astigmatism in the WF-guided group compared to the WF-optimized group that did not reach statistical significance at postoperative month $6(0.14 \pm 0.17 \mathrm{D}$ vs $0.34 \pm 0.26 \mathrm{D} ; P=0.07)$, but this trend did not persist at 12 months $(0.20 \pm 0.27 \mathrm{D}$ vs $0.23 \pm 0.33 \mathrm{D}$; $P=1.00$ ) (Table 2). At 12 months there were also no differences in the frequencies with which each group achieved astigmatism $<0.50 \mathrm{D}$ and $<1.00 \mathrm{D}(P>0.05)$ (Figure $2 \mathrm{C}$ and $\mathrm{D}$ ). 
A
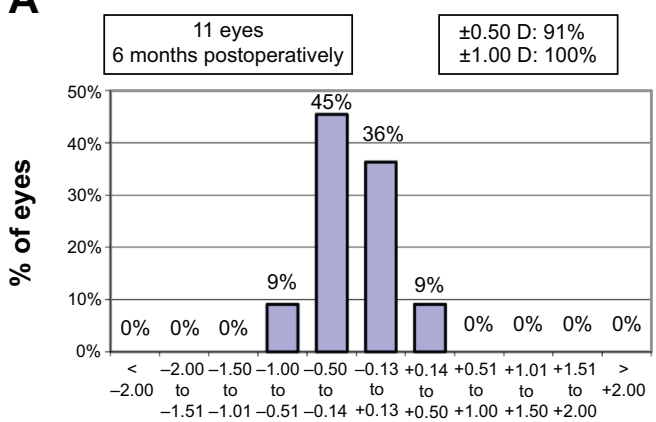

Postoperative spherical equivalent refraction (D)

Wavefront-guided hyperopic LASIK spherical equivalent refraction accuracy

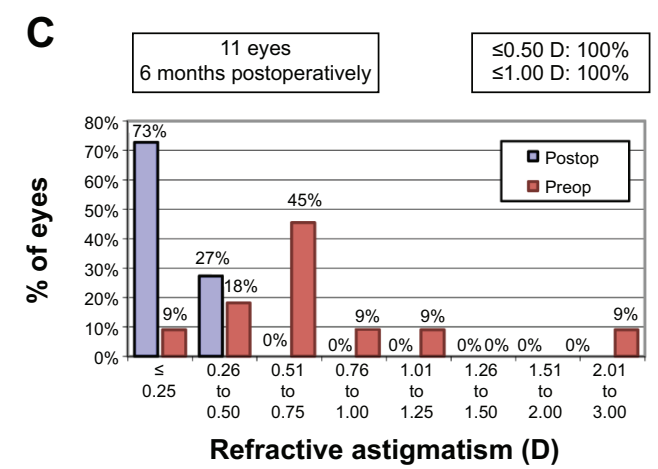

Wavefront-guided hyperopic LASIK refractive astigmatism

E

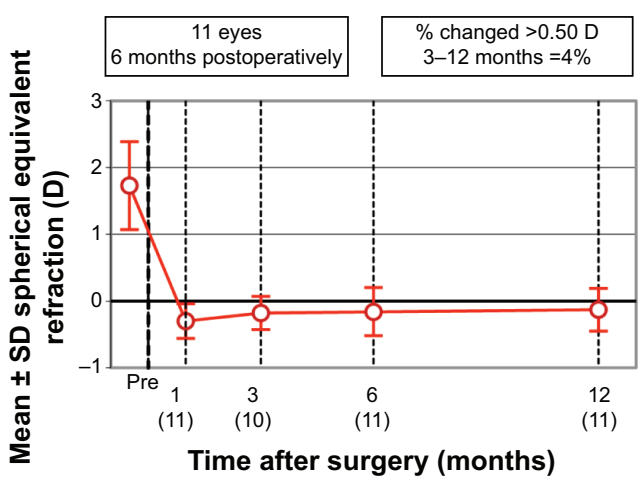

Wavefront-guided hyperopic LASIK stability of spherical equivalent refraction

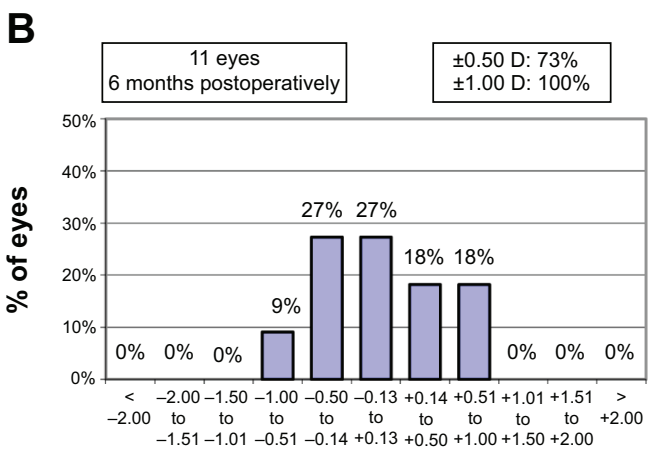

Postoperative spherical equivalent refraction (D)

Wavefront-optimized hyperopic LASIK spherical equivalent refraction accuracy

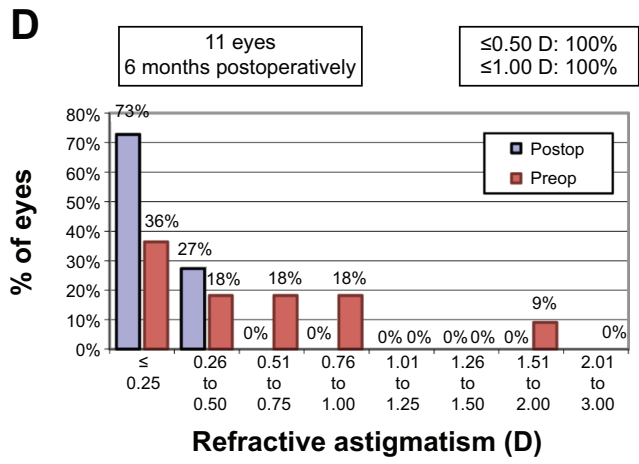

Wavefront-optimized hyperopic LASIK refractive astigmatism

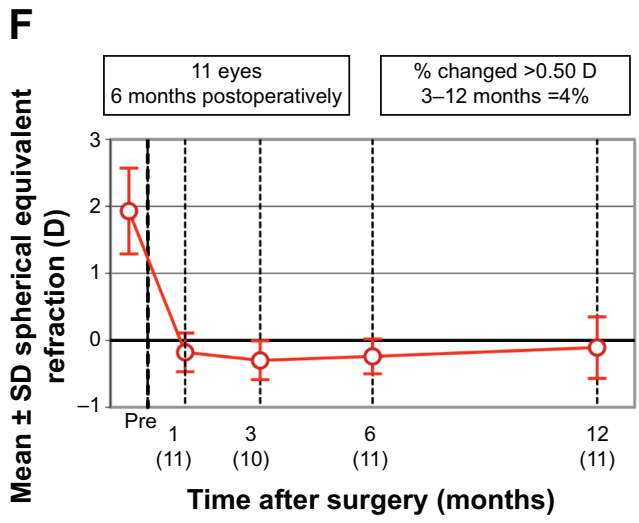

Wavefront-optimized hyperopic LASIK stability of spherical equivalent refraction

Figure 2 Comparison of WF-guided LASIK and WF-optimized LASIK standard graphs, continued.

Notes: (A) Spherical equivalent refractive accuracy after WF-guided LASIK at 12 months. (B) Spherical equivalent refractive accuracy after WF-optimized LASIK at 12 months. (C) Refractive astigmatism after WF-guided LASIK at I2 months. (D) Refractive astigmatism after WF-optimized LASIK at I2 months. (E) Stability of spherical equivalent refraction after WF-guided LASIK between I and I 2 months. (F) Stability of spherical equivalent refraction after WF-optimized LASIK between I and I 2 months. The number of eyes is shown in brackets.

Abbreviations: D, diopter; LASIK, laser in situ keratomileusis; Preop, preoperative; Postop, postoperative; SD, standard deviation; WF, wavefront.

\section{Higher order aberrations}

There were no statistically significant differences in coma, trefoil, and higher order root mean square (RMS) error between the groups postoperatively (all $P>0.05$ ). RMS error decreased in both WF-guided and WF-optimized groups at
12 months compared to preoperative measurements, but neither of these changes reached statistical significance (preoperative vs 12 months: WF-guided, $0.35 \pm 0.15$ vs $0.26 \pm 0.10$ points; WF-optimized, $0.36 \pm 0.17 \mu \mathrm{m}$ vs $0.29 \pm 0.13 \mu \mathrm{m}$; $P=0.07, P=0.13$, respectively). 


\section{Subjective parameters}

There were no statistically significant differences in subjective parameters between the groups at postoperative month 12. However, there were trends that did not reach statistical significance for night and day clarity, which were approximately three-quarters of a severity point lower for both parameters in the WF-guided group compared to the WF-optimized group (night clarity, $0.82 \pm 0.98$ vs $1.27 \pm 1.10$ points; day clarity, $0.82 \pm 0.87$ vs $1.36 \pm 1.21$ points; $P=0.17$, $P=0.18$, respectively). Participants more frequently preferred their WF-guided eye (45.5\%) than their WF-optimized eye (9.1\%), but this trend did not reach statistical significance either $(P=0.20)$ (Table 4).

\section{Discussion}

Although it is only a limited series of 11 participants, to the best of our knowledge, this is the first eye-to-eye comparison of WF-guided and WF-optimized LASIK for the primary treatment of hyperopia. Among 22 eyes, WF-guided LASIK did not offer any statistically significant advantages over WFoptimized LASIK for the parameters studied at postoperative months 1, 3, 6, and 12, including UDVA, CDVA, contrast sensitivity, astigmatism, SE, HOAs, efficacy, predictability, and safety (all $P>0.05$ ). However, one must consider the alternative hypothesis that there was insufficient power to detect differences between the groups that are of potential clinical importance.

Previous studies have hypothesized that both WF-guided and WF-optimized LASIK in hyperopes may have an advantage with respect to preserving low-contrast sensitivity compared to conventional LASIK., ${ }^{90}$ Our results, which exhibited a decline in contrast sensitivity at 12 months from preoperative measurements in both groups, did not confirm this postulate ( $5 \%$ contrast sensitivity: WF-guided $P=0.30$,

Table 4 Preoperative and 12 months postoperative questionnaire results ${ }^{\mathrm{a}}$ after WF-optimized and WF-guided hyperopic laser in situ keratomileusis

\begin{tabular}{|c|c|c|c|}
\hline \multirow[t]{2}{*}{ Parameter } & \multicolumn{2}{|c|}{ Mean \pm standard deviation, range } & \multirow[t]{2}{*}{$P^{b}$} \\
\hline & WF-guided $(n=I I)$ & WF-optimized $(n=I I)$ & \\
\hline \multicolumn{4}{|l|}{ Preoperative } \\
\hline Glare, night & $1.64 \pm 2.29,0-6$ & $1.64 \pm 2.29,0-6$ & 1.00 \\
\hline Glare, day & $2.00 \pm 2.53,0-7$ & $2.00 \pm 2.53,0-7$ & 1.00 \\
\hline Haze & $\mathrm{I} .82 \pm 2.7 \mathrm{I}, 0-7$ & $1.91 \pm 2.77,0-7$ & 1.00 \\
\hline Halos & $0.55 \pm I .5 \mathrm{I}, 0-5$ & $0.55 \pm I .5 \mid, 0-5$ & 1.00 \\
\hline Clarity, night & $3.45 \pm 2.94,0-8$ & $3.45 \pm 2.94,0-8$ & 1.00 \\
\hline Clarity, day & $2.36 \pm 2.66,0-8$ & $2.45 \pm 2.70,0-8$ & 1.00 \\
\hline Vision is excellent & $3.82 \pm 1.94,1-8$ & $4.36 \pm 2.34, I-8$ & 0.35 \\
\hline Dry eye & $2.27 \pm 2.10,0-5$ & $2.27 \pm 1.90,0-5$ & 1.00 \\
\hline Dry eye severity & $1.55 \pm 1.37,0-3$ & $1.73 \pm 1.27,0-3$ & 1.00 \\
\hline Foreign body sensation & $1.00 \pm 1.79,0-6$ & $1.00 \pm 1.79,0-6$ & 1.00 \\
\hline Vision fluctuates diurnally & $1.27 \pm 1.74,0-5$ & $1.36 \pm 1.86,0-5$ & 1.00 \\
\hline Difficulty due to ghosting & $0.64 \pm 1.80,0-6$ & $0.64 \pm 1.80,0-6$ & 1.00 \\
\hline \multicolumn{4}{|l|}{ I 2 months postoperative } \\
\hline Glare, night & $1.45 \pm 1.86,0-6$ & $1.45 \pm 1.86,0-6$ & 1.00 \\
\hline Glare, day & $0.91 \pm 1.38,0-4$ & $0.91 \pm 1.38,0-4$ & 1.00 \\
\hline Haze & $0.91 \pm 1.14,0-3$ & $0.91 \pm 1.04,0-3$ & 1.00 \\
\hline Halos & $0.36 \pm 0.67,0-2$ & $0.55 \pm 0.82,0-2$ & 1.00 \\
\hline Clarity, night & $0.82 \pm 0.98,0-3$ & $1.27 \pm 1.10,0-3$ & 0.17 \\
\hline Clarity, day & $0.82 \pm 0.87,0-2$ & $1.36 \pm 1.21,0-4$ & 0.18 \\
\hline Vision is excellent & $2.64 \pm 3.35,0-8$ & $3.00 \pm 2.65,0-8$ & 0.57 \\
\hline Dry eye & $1.91 \pm 1.97,0-7$ & $1.91 \pm 1.97,0-7$ & 1.00 \\
\hline Dry eye severity & $1.73 \pm 1.56,0-5$ & $1.73 \pm 1.56,0-5$ & 1.00 \\
\hline Foreign body sensation & $0.73 \pm 1.27,0-4$ & $0.64 \pm 0.8 \mathrm{I}, 0-2$ & 1.00 \\
\hline Vision fluctuates diurnally & $1.00 \pm 1.26,0-3$ & $1.18 \pm 1.54,0-4$ & 1.00 \\
\hline \multirow[t]{2}{*}{ Difficulty due to ghosting } & $0.09 \pm 0.30,0-1$ & $0.36 \pm 1.21,0-4$ & 1.00 \\
\hline & \multicolumn{3}{|c|}{ Percent, $95 \%$ confidence interval } \\
\hline Preferred eye & $45.5^{c}, 16.7-76.6$ & $9 . I^{c}, 0.01-4 \mid .3$ & $0.20^{\mathrm{d}}$ \\
\hline
\end{tabular}

Notes: ${ }^{\text {TT }}$ The means presented are from participants' responses to a validated questionnaire. The questionnaire was completed preoperatively and postoperatively at months I, 6, and 12. Participants completed the questionnaire for each eye. ${ }^{b} P$ values for means are by paired Wilcoxon signed-rank test for nonparametrically distributed data from a small sample. ${ }^{4} 45.5 \%$ of subjects ( 10 eyes) responded "Same". dP values for proportions are by Monte Carlo chi-squared statistic for data from a small sample. Abbreviation: WF, wavefront. 
WF-optimized $P=0.04 ; 25 \%$ contrast sensitivity: WF-guided $P=0.09$, WF-optimized $P=0.14$ ). Moreover, comparison of the WF-guided and WF-optimized groups suggests that there was no difference in the extent to which they were associated with a decline in contrast sensitivity ( $5 \%$ contrast sensitivity $P=0.60,25 \%$ contrast sensitivity $P=1.00$ ).

Studies of myopes have concluded that WF-guided approaches may yield small, but statistically significant advantages in reducing total HOAs induced by laser ablation compared to WF-optimized approaches. ${ }^{11-14}$ Our series did not find such a difference in RMS error at 12 months nor did it detect a potential trend $(P=0.44)$ raising the question of whether surgically induced higher order aberrations are affected differently by WF algorithms in hyperopes compared to myopes. Our results may also contradict the increase in total HOAs that others have observed after WF-guided LASIK in hyperopes ${ }^{10}$ and support the decrease in total HOAs that has been observed after WF-optimized treatments. ${ }^{9,15}$ For both WF-guided and WF-optimized treated eyes, RMS error was lower at postoperative month 12 compared to baseline, but these improvements did not reach statistical significance ( $P=0.07, P=0.13$, respectively). The trend observed in both groups may be due to increased corneal asphericity following hyperopic ablations, which render the cornea more prolate.

We randomized contralateral eyes to WF-guided and WF-optimized platforms because fellow eyes in the same individual are generally accepted to have more similar wound healing and corneal biomechanical properties than pairs of eyes from different individuals. Our use of the femtosecond laser may have had the effect of further reducing possible confounding variables. A recent meta-analysis comparing IntraLase to microkeratomes found no difference in efficacy or safety, but reported a statistically significant improvement in predictability with IntraLase (within $\pm 0.50 \mathrm{D}$ of target refraction). ${ }^{16} \mathrm{~A}$ second meta-analysis comparing femtosecond LASIK to mechanical microkeratome LASIK found no difference in efficacy, accuracy, or safety, but reported a statistically significant lower induction of total higher order aberrations and spherical aberration with femtosecond LASIK. ${ }^{17}$ Despite its strengths of being prospective, randomized, and having 12 months of follow-up, our series had insufficient statistical power to make robust conclusions. The small size of our series may have also contributed to the potential bias introduced by a computerized randomization schedule, which despite being random, allocated a greater proportion of dominant eyes to the WF-guided group compared to the WF-optimized group $(P=0.03)$. To assess the effect this may have had on our results, we conducted multivariate regression analyses for various outcome variables, including UDVA, CDVA, contrast sensitivity, astigmatism, SE, RMS error, and subjective survey responses, with distance dominance and WF ablation modality (WF-guided vs WF-optimized) selected as predictor variables. The results of these analyses did not change our conclusions. Another potential limitation of this study was our omission of an angle kappa assessment from the initial patient evaluation. If unrecognized, eyes with an angle kappa can result in ablations that are offset from the pupil center, and in turn, may in some cases affect refractive outcomes.

Based on this small, prospective comparative series of 22 eyes, we conclude that WF-guided and WF-optimized LASIK performed on hyperopic patients with or without astigmatism can provide similar results for the parameters of safety, contrast sensitivity, and refractive error. It is possible that WF-guided treatments offer some advantages over WFoptimized treatments, but this series lacked sufficient power to detect such differences if they were present. It will be of interest whether future studies with larger samples confirm our postulates, which should be interpreted with caution. Longer follow-up of this cohort may also prove instructive.

\section{Disclosure}

CSS has no conflicts of interest in this work. EEM owns equity in Calhoun Vision, Inc.; Refresh Innovations, Inc.; Krypton Vision, Inc.; Seros Medical, LLC; and Veralas, Inc. $\mathrm{He}$ is also a consultant for Best Doctors, Gerson Lehrman, and Oculeve, Inc.

\section{References}

1. Nanba A, Amano S, Oshika T, et al. Corneal higher order wavefront aberrations after hyperopic laser in situ keratomileusis. J Refract Surg. 2005;21:46-51.

2. Llorente L, Barbero S, Merayo J, Marcos S. Total and corneal optical aberrations induced by laser in situ keratomileusis for hyperopia. J Refract Surg. 2004;20:203-216.

3. Hersh PS, Fry K, Blaker JW. Spherical aberration after laser in situ keratomileusis and photorefractive keratectomy. Clinical results and theoretical models of etiology. J Cataract Refract Surg. 2003;29:2096-2104.

4. Llorente L, Barbero S, Cano D, Dorronsoro C, Marcos S. Myopic versus hyperopic eyes: axial length, corneal shape and optical aberrations. $J$ Vis. 2004;4:288-298.

5. Desai RU, Jain A, Manche EE. Long-term follow-up of hyperopic laser in situ keratomileusis correction using the Star S2 excimer laser. J Cataract Refract Surg. 2008;34:232-237.

6. Chan A, Manche EE. Effect of preoperative pupil size on quality of vision after wavefront-guided LASIK. Ophthalmology. 2011;118:736-741.

7. Golas L, Manche EE. Dry eye after laser in situ keratomileusis with femtosecond laser and mechanical keratome. J Cataract Refract Surg. 2011;37:1476-1480.

8. Manche EE, Haw WW. Wavefront-guided laser in situ keratomileusis (LASIK) versus wavefront-guided photorefractive keratectomy (Prk): a prospective randomized eye-to-eye comparison (an American Ophthalmological Society thesis). Trans Am Ophthalmol Soc. 2011; 109:201-220 
9. Durrie DS, Smith RT, Waring GO 4th, Stahl JE, Schwendeman FJ. Comparing conventional and wavefront-optimized LASIK for the treatment of hyperopia. J Refract Surg. 2010;26:356-363.

10. Keir NJ, Simpson T, Hutchings N, Jones L, Fonn D. Outcomes of wavefront-guided laser in situ keratomileusis for hyperopia. J Cataract Refract Surg. 2011;37:886-893.

11. Brint SF. Higher order aberrations after LASIK for myopia with Alcon and wavelight lasers: a prospective randomized trial. J Refract Surg. 2005;21:S799-S803.

12. Moshirfar M, Betts BS, Churgin DS, et al. A prospective, randomized, fellow eye comparison of WaveLight (R) Allegretto Wave (R) Eye-Q versus VISX CustomVue STAR S4 IR in laser in situ keratomileusis (LASIK): analysis of visual outcomes and higher order aberrations. Clin Ophthalmol. 2011;5:1339-1347.

13. Padmanabhan P, Mrochen M, Basuthkar S, Viswanathan D, Joseph R. Wavefront-guided versus wavefront-optimized laser in situ keratomileusis: contralateral comparative study. J Cataract Refract Surg. 2008;34:389-397.
14. Tran DB, Shah V. Higher order aberrations comparison in fellow eyes following IntraLase LASIK with wavelight allegretto and custom cornea LADArvision4000 systems. J Refract Surg. 2006;22:S961-S964.

15. Bababeygy SR, Zoumalan CI, Chien FY, Manche EE. Wavefront-guided laser in situ keratomileusis retreatment for consecutive hyperopia and compound hyperopic astigmatism. J Cataract Refract Surg. 2008;34: 1260-1266.

16. Chen S, Feng Y, Stojanovic A, Jankov MR 2nd, Wang Q. IntraLase femtosecond laser vs mechanical microkeratomes in LASIK for myopia: a systematic review and meta-analysis. $J$ Refract Surg. 2012;28:15-24.

17. Zhang ZH, Jin HY, Suo Y, et al. Femtosecond laser versus mechanical microkeratome laser in situ keratomileusis for myopia: metaanalysis of randomized controlled trials. J Cataract Refract Surg. 2011;37: 2151-2159.
Clinical Ophthalmology

\section{Publish your work in this journal}

Clinical Ophthalmology is an international, peer-reviewed journal covering all subspecialties within ophthalmology. Key topics include: Optometry; Visual science; Pharmacology and drug therapy in eye diseases; Basic Sciences; Primary and Secondary eye care; Patient Safety and Quality of Care Improvements. This journal is indexed on

\footnotetext{
Submit your manuscript here: http://www.dovepress.com/clinical-ophthalmology-journal
}

\section{Dovepress}

PubMed Central and CAS, and is the official journal of The Society of Clinical Ophthalmology (SCO). The manuscript management system is completely online and includes a very quick and fair peer-review system, which is all easy to use. Visit http://www.dovepress.com/ testimonials.php to read real quotes from published authors. 